\title{
Erratum: "Use of Oxidation and Reduction Vapor Generation for Lowering the Detection Limits of Iodine in Biological Samples by Inductively Coupled Plasma Atomic Emission Spectrometry" [Journal of Analytical Chemistry (2), 64 (2009)]
}

\author{
E. A. Vtorushina ${ }^{a}$, A. I. Saprykin ${ }^{a}$, and G. Knapp ${ }^{b}$ \\ ${ }^{a}$ Nikolaev Institute of Inorganic Chemistry, Siberian Branch, Russian Academy of Sciences \\ pr. Akad. Lavrent'eva 3, Novosibirsk, 630090 Russia \\ ${ }^{b}$ Graz University of Technology, Technikerstrasse 4, Graz, A-8010 Austria \\ Received May 15, 2009
}

DOI: $10.1134 / \mathrm{S} 1061934809070193$

1. On p. 131, left column, the last line of the third paragraph should read:

$$
2 \mathrm{IO}_{3}^{-}+7 \mathrm{H}_{2} \mathrm{O}_{2}+2 \mathrm{H}^{+}=\mathrm{I}_{2}+6 \mathrm{O}_{2}+8 \mathrm{H}_{2} \mathrm{O} .
$$

2. Throughout the text

microwave combustion in an oxygen flow should read microwave-induced oxygen combustion and periodate ion $\left(\mathrm{IO}_{4}^{-}\right)$should read iodate ion $\left(\mathrm{IO}_{3}^{-}\right)$. 